University of Wollongong

Research Online

Faculty of Engineering and Information

Faculty of Engineering and Information

Sciences - Papers: Part A

Sciences

$1-1-2016$

\title{
Modelling long-term deformation of granular soils incorporating the concept of fractional calculus
}

Yifei Sun

University of Wollongong, ys910@uowmail.edu.au

Yang Xiao

Chongqing University, hhuxyanson@163.com

Changjie Zheng

University of Newcastle

Khairul Fikry Hanif

University of Western Australia

Follow this and additional works at: https://ro.uow.edu.au/eispapers

Part of the Engineering Commons, and the Science and Technology Studies Commons

Research Online is the open access institutional repository for the University of Wollongong. For further information contact the UOW Library: research-pubs@uow.edu.au 


\title{
Modelling long-term deformation of granular soils incorporating the concept of fractional calculus
}

\author{
Abstract \\ Many constitutive models exist to characterise the cyclic behaviour of granular soils but can only \\ simulate deformations for very limited cycles. Fractional derivatives have been regarded as one potential \\ instrument for modelling memory-dependent phenomena. In this paper, the physical connection between \\ the fractional derivative order and the fractal dimension of granular soils is investigated in detail. Then a \\ modified elasto-plastic constitutive model is proposed for evaluating the long-term deformation of \\ granular soils under cyclic loading by incorporating the concept of factional calculus. To describe the flow \\ direction of granular soils under cyclic loading, a cyclic flow potential considering particle breakage is \\ used. Test results of several types of granular soils are used to validate the model performance.

\section{Disciplines} \\ Engineering | Science and Technology Studies

\section{Publication Details} \\ Sun, Y., Xiao, Y., Zheng, C. \& Hanif, K. Fikry. (2016). Modelling long-term deformation of granular soils \\ incorporating the concept of fractional calculus. Acta Mechanica Sinica, 32 (1), 112-124.
}




\title{
Modelling long-term deformation of granular soils incorporating the concept of fractional calculus
}

\author{
Yifei Sun ${ }^{1} \cdot$ Yang Xiao $^{2} \cdot$ Changjie Zheng $^{3} \cdot$ Khairul Fikry Hanif $^{4}$
}

Received: 24 June 2015 / Revised: 28 June 2015 / Accepted: 16 July 2015 / Published online: 29 July 2015 (C) The Chinese Society of Theoretical and Applied Mechanics; Institute of Mechanics, Chinese Academy of Sciences and Springer-Verlag Berlin Heidelberg 2015

\begin{abstract}
Lots of constitutive models exist to characterise the cyclic behaviour of granular soils but can only simulate deformations for very limited cycles. Fractional derivatives have been regarded as one potential instrument for modelling memory-dependent phenomena. In this paper, the physical connection between the fractional derivative order and the fractal dimension of granular soils is investigated in detail. Then a modified elasto-plastic constitutive model is proposed for evaluating the long-term deformation of granular soils under cyclic loading by incorporating the concept of factional calculus. To describe the flow direction of granular soils under cyclic loading, a cyclic flow potential considering particle breakage is used. Test results of several types of granular soils are used to validate the model performance.
\end{abstract}

Keywords Constitutive model · Fractional order · Fractional calculus · Long-term deformation

\section{Introduction}

Static and cyclic stress strain responses of granular soils have long been a critical issue that attract many researchers' attention. Lots of experimental and theoretical studies have been performed [1-14] to investigate the mechanical behaviour of granular soils. For example, Xiao et al. [15] conducted a series of true triaxial tests on the rockfill material under drained loading condition. Khalili et al. [7] and Liu et al. [16] studied the cyclic behaviour of gravelly soil under cyclic loading with low frequency. Suiker et al. [10] and Indraratna et al. [17, 18] investigated the deformation and degradation behaviours of both ballast and subballast under static and cyclic loading, from which the influences of loading history and confining pressure as well as loading frequency were observed. These notable contributions provide fundamental tools for further constitutive modelling of the cyclic behaviour of granular soils.

Corresponding author: Yang Xiao hhuxyanson@163.com

1 Faculty of Engineering and Information Sciences; Univ. of Wollongong, Wollongong, NSW 2522, Australia

2 College of Civil Engineering; Chongqing Univ., Chongqing 400450, China

3 ARC Centre of Excellence for Geotechnical Science and Engineering; Univ. of Newcastle, Newcastle, NSW 2308, Australia

4 Faculty of Engineering, Computing and Mathematics; Univ. of Western Australia, Perth 6907, Australia
Up until now, constitutive models have been developed based on various concept, including the incremental theory [19], fractal theory [20, 21], shear strain and kinematic hardening theories $[8,16,22]$, and the bounding surface plasticity [7, 12, 23]. Some of the models [8, 14, 23] can simulate the real stress strain behaviour but are complex, whereas others $[6,12]$ are relatively simple but cannot take into account the deformation and degradation of granular soils under complicated loading conditions. Most importantly, these models $[7,16]$ can only simulate the cyclic behaviour of granular soils for very limited loading cycles, say less than 100 cycles. For the long-term strain under high loading cycles $\left(N>10^{3}\right)$, these models usually failed due to the unintentional accumulation of numerical errors and the huge calculation effort, especially in the finite element analysis. There is little possibility for these theoretical models to be used in practical engineering where the loads usually have at least tens of thousands of cycles. To overcome this limitation, lots of empirical and semiempirical models were proposed. For example, Indraratna et al. [22] proposed a sophisticated elasto-plastic model by introducing empirical parameters to consider the effect of particle breakage, stress ratio, and number of loading cycles. In fact, the permanent deformation of granular soils under cyclic loading is not only influenced by the current loading stress but also affected by previous loading cycles. It is indeed a memory-intensive and path-dependent phenomenon which might be mathematically represented by using the concept of fractional calculus [24-26] . By using the fractional calculus theory [27-29], Yin et al. [25, 26] successfully proposed a framework for modelling strain hardening and softening of geomaterials. The model could be easily incorporated in engineering-oriented finite element method due to its explicit expression. However, their model was just phenomenological, and the physical origin of the fractional order still remains unknown and open for discussion. Most importantly, the model only dealt with the mechanical behaviour under static loading. For soils tested under cyclic loading, lots of efforts still need to be done.

The aim of this paper is to investigate the physical origin of the fractional derivative order, and then develop a more rigorous constitutive model for granular soils subjected to cyclic loading by incorporating the theory of fractional calculus. The ability of the proposed model in predicting long-term deformation with a large number of loading cycles is demonstrated by simulating a series of long-term cyclic tests. 


\section{Notations and definitions}

\subsection{Notations}

In the model presented, granular soils are assumed to be homogeneous. Both the elastic and elastic-plastic responses are isotropic. Compression is considered to be positive and tension is negative. Each stress notation here represents a corresponding effective stress unless otherwise specified. For simplicity, the following triaxial stress notations are used:

$$
\begin{gathered}
p=\frac{1}{3}\left(\sigma_{1}+2 \sigma_{3}\right) \\
q=\sigma_{1}-\sigma_{3} \\
\sigma=[p, q]^{T}
\end{gathered}
$$

where $p$ and $q$ denote the mean principal stress and deviator stress, respectively. $\sigma_{1}$ and $\sigma_{3}$ denote the first and third principal stresses, respectively. $\sigma$ is the effective stress tensor. The corresponding volumetric strain $\varepsilon_{v}$, generalised shear strain $\varepsilon_{S}$, and generalised total strain $\varepsilon_{t}$ can be given as

$$
\begin{gathered}
\varepsilon_{v}=\varepsilon_{1}+2 \varepsilon_{3} \\
\varepsilon_{s}=\frac{2}{3}\left(\varepsilon_{1}-\varepsilon_{3}\right) \\
\varepsilon_{t}=\sqrt{\varepsilon_{1}^{2}+2 \varepsilon_{3}^{2}} \\
\varepsilon=\left[\varepsilon_{v}, \varepsilon_{s}\right]^{T}
\end{gathered}
$$

where $\varepsilon_{1}$ and $\varepsilon_{3}$ are the first and third principal strains, respectively. $\boldsymbol{\varepsilon}$ is the strain tensor. The increments of the total strain under each loading step can be decomposed into elastic and plastic parts according to

$$
\dot{\boldsymbol{\varepsilon}}=\dot{\boldsymbol{\varepsilon}}^{e}+\dot{\boldsymbol{\varepsilon}}^{p}
$$

where a superimposed dot indicates an increment; the superscripts $e$ and $p$ denote the elastic and plastic components, respectively.

\subsection{Definitions}

The fractional calculus theory deals with both fractional derivatives and integrals. In this work, two common definitions of the fractional derivative and fractional integral, known as the Riemann-Liouville fractional derivative and integral, will be used.

The Riemann-Liouville fractional derivative can be formulated as

$$
{ }_{0} D_{x}^{\alpha} z(x)=\frac{d^{\alpha} z(x)}{d x^{\alpha}}=\frac{1}{\Gamma(1-\alpha)} \frac{d}{d x} \int_{0}^{x} \frac{z(\tau) d \tau}{(x-\tau)^{\alpha}}, \quad x>0
$$

where $D$ means derivation; $\alpha$ is the fractional order, ranging from 0 to $1 . x$ denotes the independent variable and can be regarded as the loading time in static test or the loading cycles in cyclic test. Due to its integral definition of the derivative, the fractional order derivative has a strong memory of the variable, $x$. Accordingly, there is one particular difference between the integer order derivative and the fractional order derivative. The integer order derivative of a constant is 0 , whereas the Riemann-Liouville fractional order derivative of a constant $C$ is not equal to 0 , but

$$
{ }_{0} D_{x}^{\alpha} C=\frac{C x^{-\alpha}}{\Gamma(1-\alpha)}
$$

where the gamma function $\Gamma(\bullet)$ is defined as

$$
\begin{gathered}
\Gamma(x)=\int_{0}^{\infty} e^{-\tau} \tau^{x-1} d \tau \\
\Gamma(x+1)=x \Gamma(x)
\end{gathered}
$$

Another important formula, the Riemann-Liouville fractional integral is defined as

$$
{ }_{0} I_{x}^{\alpha} z(x)=\frac{1}{\Gamma(\alpha)} \int_{0}^{x} \frac{z(\tau) \mathrm{d} \tau}{(x-\tau)^{1-\alpha}}, \quad x>0
$$

where $I$ means integral. Note that there are two important properties for the Riemann-Liouville definition, one is

$$
{ }_{0} D_{x}^{\alpha-\varsigma} Z(x)={ }_{0} D_{x}^{\alpha}\left({ }_{0} I_{x}^{\varsigma} Z(x)\right)
$$

which means that the Riemann-Liouville derivative operator is a left inverse to the Riemann-Liouville integral operator in current situation. However, the fractional derivative and integral do not commute as shown in the following Eq. (14)

$$
{ }_{0} I_{x}^{\varsigma}\left({ }_{0} D_{x}^{\alpha} z(x)\right)=\frac{d^{\alpha-\varsigma} z(x)}{d x^{\alpha-\varsigma}}-\left.\frac{d^{\alpha-1} z(x)}{d x^{\alpha-1}}\right|_{x=0} \frac{x^{\varsigma-1}}{\Gamma(\varsigma)}
$$

\section{Connections between the fractional order and fractal dimension}

\subsection{Static loading condition}

To quantify the soil property, laboratory tests, including the oedometric, biaxial, and triaxial tests with either constant stress rate or constant strain rate, are usually conducted. Various constitutive models concerning the stress strain behaviours under these conditions were proposed. By regarding the soil as an intermediate material, lying between 
the ideal solids which obey Hooke's law and the Newtonian fluids which satisfy Newton's law of viscosity, Yin et al. [26] proposed a general framework for fractional order constitutive modelling of soils under static loading. For clarification, their work is briefly introduced here. The basic constitutive law of an intermediate material can be simply defined as

$$
\sigma(t)=E \theta^{\alpha}{ }_{0} D_{t}^{\alpha} \varepsilon(t), \quad 0 \leq \alpha \leq 1
$$

where $E$ and $\theta$ are material constants. Note that the Hooke's law ( $\alpha=0)$ and Newton's law ( $\alpha=1$ ) are just the special cases of Eq. (15). For soils tested under a constant strain rate $\left(c_{1}\right)$ condition with $\varepsilon(t)=c_{1} t$, Eq. (15) can be further derived by using Riemann-Liouville definition as

$$
\sigma=\frac{c_{1} E_{1}\left(c_{1} \theta\right)^{\alpha_{1}}}{\Gamma\left(2-\alpha_{1}\right)} \varepsilon^{1-\alpha_{1}}, \quad 0 \leq \alpha_{1} \leq 1
$$

For soils tested under a constant stress rate $\left(c_{2}\right)$ condition with $\sigma(t)=c_{2} t$, Eq. (15) can be further derived as

$$
\varepsilon=\frac{\sigma^{1+\alpha_{2}}}{E_{2}\left(c_{2} \theta\right)^{\alpha_{2}} \Gamma\left(2+\alpha_{2}\right)}, \quad 0 \leq \alpha_{2} \leq 1
$$

Note that for the same soil, the fractional orders in Eqs. (16) and (17) should be correlated by $\left(1-\alpha_{1}\right)\left(1+\alpha_{2}\right)=1$. This is because the power law connection between the strain and stress should be the consistent, irrespective of the loading methods. As already validated by Yin et al. [26], the proposed model can well capture the stress strain behaviour of different geomaterials under different static loading condition even with fewer model parameters, when compared with other existing constitutive models. However, in their model, the fractional order $\alpha$ was just regarded as a material constant. No physical origins of the fractional order were proposed. In the next section, an attempt will be made to demonstrate the correlation of the fractional order with the fractal dimension of granular soils under static loading.

\subsection{Cyclic loading condition}

There are three common approaches in modelling the cyclic behaviour of granular soils. The first is the traditional theoretical method, including the elasto-plastic $[7,16]$ and elasto-visco-plastic models [30, 31], where the deformation of each loading cycle is strictly counted. This method reveals the deformation mechanism of soils subjected to cyclic loading. However, it cannot be used to predict the long-term deformation with large amount of loading cycles, due to the intrinsic accumulation of numerical errors with increasing loading steps. The second is the semi-empirical method [2, 22, 32, 33], where the theoretical models are modified by incorporating empirical equations to provide a better simulation of the cumulative deformation for a large number of cycles. However, these models usually have a lot of model parameters and therefore are hardly to be used in practical engineering. The third is the pure empirical method, which is usually problem targeted and flexible for engineering application. However, it does not reflect the essential mechanism behind the deformation phenomenon of granular soils. The cyclic behaviour of granular soils is actually a history-dependent phenomenon where the current soil deformation is often influenced by the previous loading history. The fractional derivative may be acted as an alternative way in modelling the cyclic behaviour of soils considering its definition in an integral form.
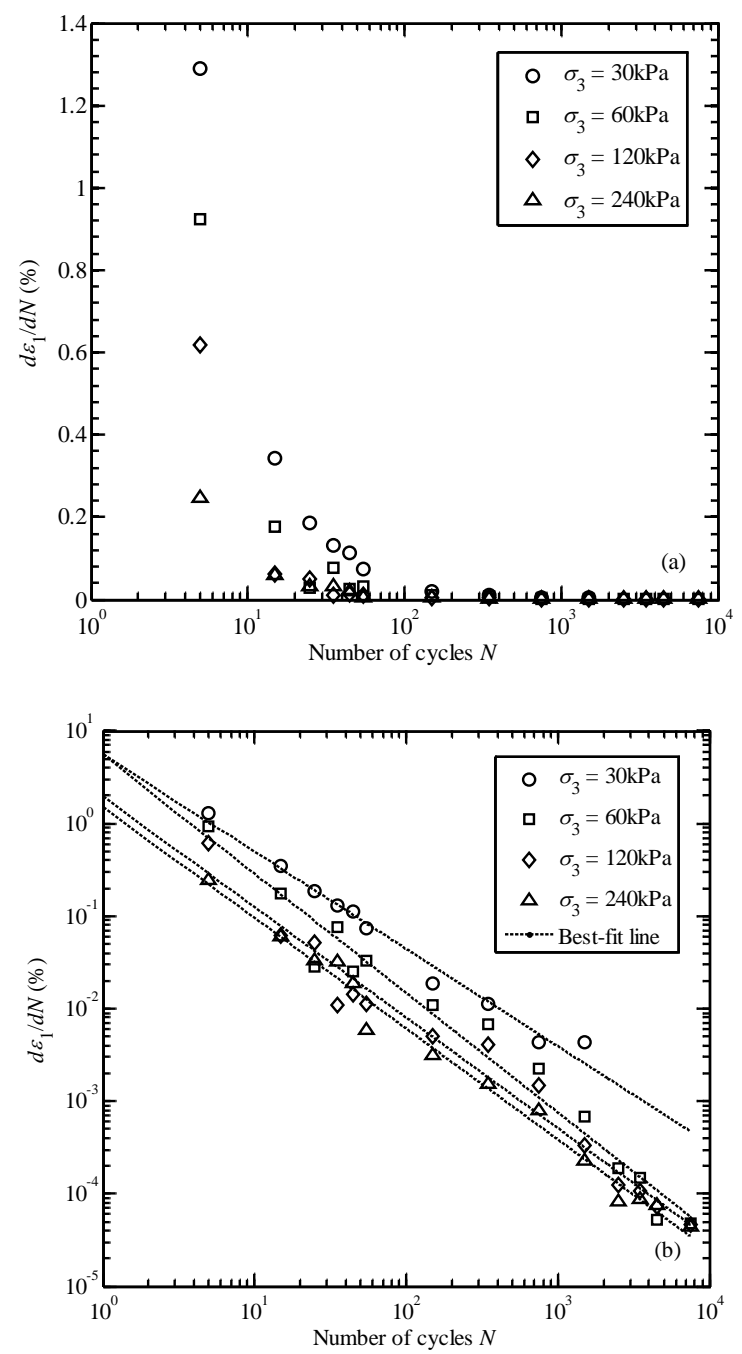

Fig. 1 Variation of the strain accumulation rate with number of loading cycles : (a) normal scale and (b) log-scale (modified after [44])

In the context of cyclic tests, the loading cycles $N$ instead of the time $t$ is used [3,34], as the cumulative strain rate during cyclic loading means a derivative with respect to the number of $N$. Fig. 1(a) shows the variation of the axial strain accumulation rate with the number of loading cycles, where the strain accumulation rate for one close cycle of loading decreases significantly at first and then approaches stable with increasing number of loading cycles. However, 
by rephrasing the strain accumulation rate and number of loading cycles in a $\log$-log form as shown in Fig. 1(b), a simple linear variation depicted by Eq. (18) can be observed.

$$
\log \dot{\varepsilon}_{1}=-\beta \log N+\log b, \quad 0<\beta<1
$$

where $\beta$ and $b$ are fitting parameters, which remain as constant for a given loading state. As will be demonstrated later, $b$ is more likely dependent on the loading stress state, for example, $p$ and $q$ in triaxial loading condition. $\dot{\varepsilon}_{1}$ denotes the strain accumulation rate with respect to $N$, which is scale invariant and obeys the power law in relation to the number of loading cycles. Note that soil deformation only initiated when the external load applies. Therefore, the soil strain at $N=0$ is regarded as zero. By performing fractional differentiation on both sides of Eq. (18), one has the following simple and yet useful expression:

$$
\frac{d^{\alpha} \varepsilon_{1}}{d N^{\alpha}}=b \Gamma(\alpha)
$$

where the fractional derivative order $\alpha=1-\beta$.

To represent how the fractal dimension of soils determines the fractional order $\alpha$ in Eq. (19) during cyclic loading, let us assume that the plastic deformation of granular soils is only attributed to the compression and expansion of the internal pores formed by the skeleton particles within the sample.

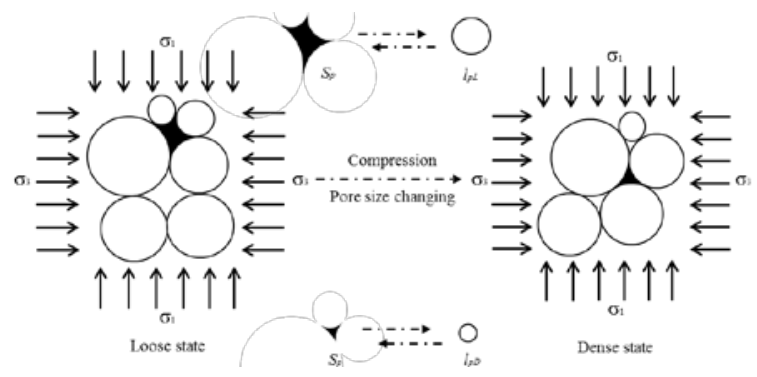

Fig. 2 Schematic representation of the equivalent pore size of granular soils under compression

As shown in Fig. 2, the pore size of a loose sample is relatively large $\left(l_{p L}\right)$ while it reduces to a small value $\left(l_{p D}\right)$ once the external loads apply. It is hardly to evaluate the true pore size distribution of a three dimensional material. However, a two dimensional theoretical approach similar to the determination of constriction (pore) size distribution of granular soils $[35,36]$ can be used to give an approximate analysis of the pore size distribution of a given granular soil. The diameter of an equivalent circle that has the same area as the shaded region shown in Fig. 2, represents the size of the pore formed by surrounding skeleton particles.

$$
l_{p}=\sqrt{\frac{4 S_{p}}{\pi}}
$$

The theoretical concepts were therefore incorporated into a comprehensive computer subroutine to compute the pore size distribution. Fig. 3 illustrates two specific pore size distributions corresponding to a given particle size distribution. As expected, the pore sizes of a loose sample are generally larger than those of a dense one. It should be noted that the calculated pore size distribution is only a qualification of the distribution of pores in the soil sample. The actual pore size distribution can only be quantified by laboratory measurement, which is not within the scope of this study. However, bear in mind that the densest pore size distribution (with relative density equal to unit) is observed to be an almost parallel shifting from an initially loose pore size distribution.

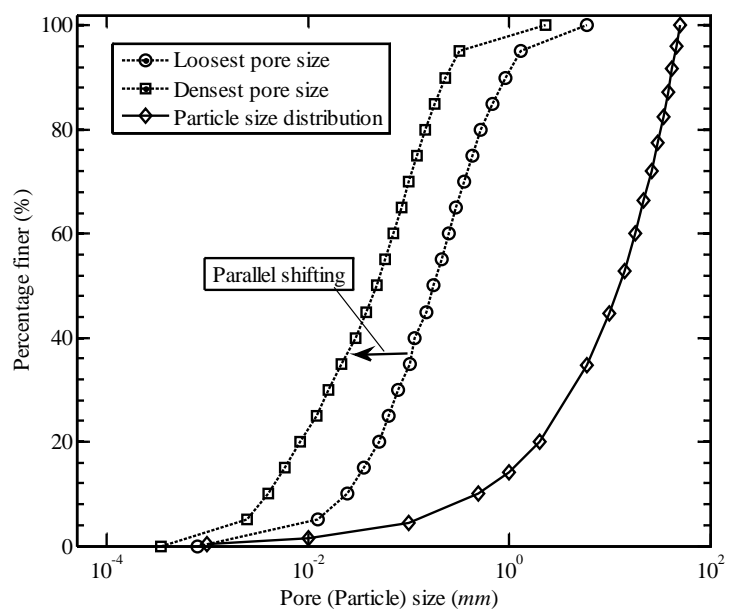

Fig. 3 Loosest and densest pore size distributions of the corresponding particle size distribution

The three dimensional pores are usually distributed in fractal law [37-39], which can be well characterized by the following formula:

$$
N_{p}\left(L>l_{p}\right)=B l_{p}^{-\Delta_{p}}
$$

where $N_{p}$ denotes the number of pores with diameters larger than $l_{p}$. B is a constant of proportionality and $\Delta_{p}$ is the fractal dimension of the internal pores. Therefore, the total surface area and volume of the internal voids can be obtained by using Eq. (21).

$$
\begin{gathered}
S_{p}=\frac{\pi \mathrm{B} \gamma_{p} \Delta_{p}}{\left(2-\Delta_{p}\right)}\left(l_{p M}^{2-\Delta_{p}}-l_{p m}^{2-\Delta_{p}}\right) \\
V_{p}=\frac{4 \pi B \gamma_{p}^{\prime} \Delta_{p}}{3\left(3-\Delta_{p}\right)}\left(l_{p M}^{3-\Delta_{p}}-l_{p m}^{3-\Delta_{p}}\right)
\end{gathered}
$$

where $\gamma_{p}$ and $\gamma_{p}^{\prime}$ denote the surface and volume shape factors of the internal pores, respectively; $l_{p M}$ and $l_{p m}$ are the current maximum and minimum pore sizes, respectively. It is assumed that the total surface areas of particles and pores are equal, given that the combined contact area of touching 
particles is very small compared to the total surface area. The following relationship between fractal dimension of soil particles, $\Delta_{S}$, and the fractal dimension of the internal pores, $\Delta_{p}$, can be given as [39]:

$$
\Delta_{p}=2+\left(\Delta_{s}-2\right) \frac{\ln \left(l_{s m} / l_{s M}\right)}{\ln \left(l_{p m} / l_{p M}\right)}
$$

where $l_{s M}$ and $l_{s m}$ are the maximum and minimum particle sizes, respectively. As already proved in Fig. 3, both the maximum and minimum pore sizes should decrease with soil compression. The change of the total pore volume should be attributed to the change of the overall pore sizes. As this topic was rarely reached, a special case of the oedometric test where $\dot{\varepsilon}_{1}=\dot{\varepsilon}_{v}$ is considered here. Therefore, the increment of axial strain accumulation can be determined by

$$
\dot{\varepsilon}_{1}=\frac{-d V_{p}}{\left(1+e_{0}\right) V_{s}}=\frac{4 \pi \mathrm{B} \gamma_{p}^{\prime} \Delta_{p}}{3\left(1+e_{0}\right) V_{s}}\left(l_{p M}^{2-\Delta_{p}} d l_{p M}-l_{p m}^{2-\Delta_{p}} d l_{p m}\right)
$$

where $V_{s}$ and $e_{0}$ are the total volume of the internal particles and the initial void ratio, respectively. Due to the parallel shifting of the pore size distribution, the maximum and minimum particle sizes should vary simultaneously by decreasing $k$ times from their initial values. This can be also validated by ensuring the equality of Eq. (24), supposing the fractal dimensions of both the pores and particles are invariable. Eq. (25) can be further derived as

$$
\dot{\varepsilon}_{1}=-\mu k^{\Delta_{p}-4} \frac{\partial k}{\partial N}
$$

where the material constant $\mu$ is expressed as

$$
\mu=\frac{4 \pi \mathrm{B} \gamma_{p}^{\prime} \Delta_{p}}{3\left(1+e_{0}\right) V_{s}}\left(l_{p M_{0}}^{3-\Delta_{p}}-l_{p m_{0}}^{3-\Delta_{p}}\right)
$$

in which $l_{p M_{0}}$ and $l_{p m_{0}}$ are the initial maximum and minimum pore sizes within the sample. The decreasing rate $k$ changes with the number of loading cycles. By recalling the relationship shown in Eq. (18), and comparing the exponent with that of Eq. (26), an explicit expression for $k$ can be obtained as

$$
k=\left[\left(3-\Delta_{p}\right) \alpha^{-1} N^{\alpha}+1\right]^{1 /\left(\Delta_{p}-3\right)}
$$

As can be observed in Eq. (28), both the fractional derivative order $\alpha$ and the fractal dimension $\Delta_{p}$ influence the performance of $k$. Fig. 4 represents the evolution of the function $k$ and the normalized total volume of the internal pores. The function $k$ is observed to increase significantly when the number of loading cycles is small. However, the total volume of internal pores decreases rapidly at the initial thousands of loading cycles and soon becomes stable, implying that large cumulative deformation usually occurs at the initial loading stage. This is in accordance with the experimental observations by Suiker et al. [10, 32].

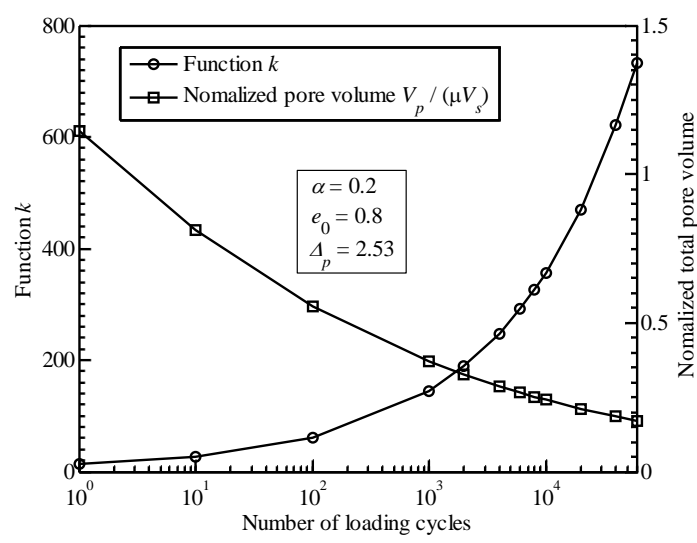

Fig. 4 Variation of the function $k$ and normalized total volume of internal pores

The physical connection between the fractional derivative order $(\alpha)$ and the fractal dimension $\left(\Delta_{S}\right)$ can be obtained by using Eqs. (24) and (28) with $N$ equal to 1 .

$$
\alpha=\left(\Delta_{s}-2\right) \vartheta+\chi
$$

where parameters $\vartheta=-\chi \ln \left(l_{s m} / l_{s M}\right) / \ln \left(l_{p m} / l_{p M}\right)$ and $\chi^{-1}=1-k_{1}^{\Delta_{p}-3} ; k_{1}$ corresponds to the decreasing rate of the first loading cycle. Therefore, the fractional derivative order decreases with the increasing fractal dimension of a given granular soil, indicating that soils with higher fractal dimensions are more hardly to be compacted when compared with those with lower fractal dimensions. The changing rate depends on the value of $\vartheta$.

\section{Constitutive model incorporating fractional calculus}

4.1General constitutive equations

The total increments of strains can be decomposed into the incremental plastic strain and elastic strain, respectively. Following the traditional elastic theory, the incremental elastic stress can be expressed as

$$
\dot{\boldsymbol{\varepsilon}}^{e}=\mathbf{C}^{e} \dot{\boldsymbol{\sigma}}
$$

where $\mathbf{C}^{e}$ is the elastic compliance matrix, which can be defined by the the bulk and shear moduli of the sample:

$$
\mathbf{C}^{e}=\left[\begin{array}{ll}
1 / K & \\
& 1 / 3 G
\end{array}\right]
$$

where $K$ and $G$ are expressed as 


$$
\begin{gathered}
G=G_{0} p_{a} \frac{(2.97-e)^{2}}{1+e} \sqrt{\frac{p}{p_{a}}} \\
K=\frac{2 G(1+v)}{3(1-2 v)}
\end{gathered}
$$

in which $v$ is the Poisson ratio. As demonstrated before, the strain accumulation behaviour can be better described by using fractional order derivatives. The strain accumulation rate remains scale invariant when represented in the scale of $N^{\alpha-1}$. Therefore, instead of the traditional incremental definition of the accumulation rate [32, 34], the cumulative soil strain $\varepsilon^{p}$ can be fractionally defined as

$$
\frac{d^{\alpha} \varepsilon^{p}}{d N^{\alpha}}=d \bar{\varepsilon}^{p} \mathbf{m}
$$

where $\mathbf{m}$ denotes the flow direction of the cumulative strain, which can be derived from a loading function. $d \bar{\varepsilon}^{p}$ is the flow intensity. Note that Eq. (33) degrades to the form of the high-cycle accumulation model [3, 33] with $\alpha=1$. During triaxial cyclic loading, the deformation of granular soils $\left(\varepsilon^{p}\right)$ is usually decomposed into a shearing-related component $\varepsilon_{s}^{p}$ and a compaction-related component $\varepsilon_{v}^{p}$, which yields

$$
\begin{gathered}
\frac{d^{\alpha} \varepsilon_{s}^{p}}{d N^{\alpha}}=d \lambda \frac{\partial g}{\partial q} \\
\frac{d^{\alpha} \varepsilon_{v}^{p}}{d N^{\alpha}}=d \lambda \frac{\partial g}{\partial p}
\end{gathered}
$$

where $g$ is the loading function and $d \lambda$ is the modified plastic multiplier that can be related to the flow intensity as follows

$$
d \bar{\varepsilon}^{p}=d \lambda\left\|\frac{\partial g}{\partial \boldsymbol{\sigma}}\right\|
$$

$\|\bullet\|$ represents the module of a tensor. Determination of the plastic multiplier and flow intensity will be given in the following section.

\subsection{Loading function and flow direction}

As granular soils, such as the rockfill and ballast, usually undergo internal particle breakage during loading, a loading surface function considering the effect of particle breakage on the mechanical response is used [40]:

$$
g=\left(\frac{q}{M p}\right)^{a+1}+\ln \left(\frac{p}{p_{0}}\right)^{a+1}=0
$$

where parameter $a(\geq 0)$ reflects the effect of particle breakage. $p_{0}$ denotes the size of the current loading surface. $M$ denotes the critical state friction parameter and can be obtained by using $M=6 \sin \phi /(3-\operatorname{Sin} \phi)$ where $\phi$ is the critical state friction angle. Detailed derivations of Eq. (36) can be found elsewhere in McDowell [40]. By recalling Eq. (18), $d \lambda \partial g / \partial \sigma$ should remain as constant for a given loading state. Therefore, applying the derivation of $1-\alpha$ order to both sides of Eq. (34), one has

$$
f=\frac{\dot{\varepsilon}_{v}^{p}}{\dot{\varepsilon}_{S}^{p}}={ }_{0} D_{N}^{1-\alpha}\left[d \lambda \frac{\partial g}{\partial p}\right] /{ }_{0} D_{N}^{1-\alpha}\left[d \lambda \frac{\partial g}{\partial q}\right]
$$

which can be regarded as the cyclic flow rule of granular soils. $\eta=q / p$ is the stress ratio. Similar concepts of the cyclic flow rule can be found elsewhere in [2]. Accordingly, the flow direction can be defined as

$$
\mathbf{m}=\left[m_{p}, m_{q}\right]^{T}=\left[\frac{f}{\sqrt{1+f^{2}}}, \frac{1}{\sqrt{1+f^{2}}}\right]^{T}
$$

\subsection{Hardening rule}

Applying the consistency condition at the loading surface and assuming isotropic hardening of the loading surface with the plastic volumetric compression, the derivative of the loading surface can be obtained as

$$
\frac{\partial g}{\partial p} \dot{p}+\frac{\partial g}{\partial q} \dot{q}+\frac{\partial g}{\partial p_{0}} \frac{\partial p_{0}}{\partial \varepsilon_{v}^{p}} \dot{\varepsilon}_{v}^{p}=0
$$

By recalling Eq. (34), the plastic volumetric strain $\dot{\varepsilon}_{v}^{p}$ can be rewritten as

$$
\dot{\varepsilon}_{v}^{p}=\frac{\partial g}{\partial p} \frac{d \lambda}{\Gamma(\alpha)} N^{\alpha-1}
$$

Substituting Eq. (40) into (39), the plastic multiplier $d \lambda$ can be derived as

$$
d \lambda=-\frac{\frac{\partial g}{\partial p} \dot{p}+\frac{\partial g}{\partial q} \dot{q}}{\frac{\partial g}{\partial p_{0}} \frac{\partial p_{0}}{\partial \varepsilon_{v}^{p}} \frac{\partial g}{\partial p}} \Gamma(\alpha) N^{1-\alpha}
$$

where the relationship between $p_{0}$ and $\varepsilon_{v}^{p}$ under isotropic loading condition can be formulated as

$$
\frac{\partial p_{0}}{\partial \varepsilon_{v}^{p}}=\frac{\left(1+e_{0}\right)}{\lambda^{\prime}-\kappa} p_{0}
$$

where $\lambda^{\prime}$ and $\kappa$ are gradients of the critical state and swell lines, respectively. $e_{0}$ denotes the initial void ratio. However, 
considering the effect of loading history $(N)$, Eq. (42) can be further modified by using Eq. (16), which yields

$$
\frac{\partial p_{0}}{\partial \varepsilon_{v}^{p}}=\frac{\left(1+e_{0}\right)}{\lambda^{\prime}-\kappa} p_{0} N^{1-\alpha}
$$

Note that Eq. (43) reduces to Eq. (42) at virgin loading condition with $N=1$. Strictly speaking, the effect of cyclic loading history should be represented by internal soil variables. However, to avoid excessive complexity in constitutive equations and especially the application in numerical simulation, $N$ is included in the model formulation. A similar phenomenological approach was also used by Liu and Carter [41] and Chen et al. [42]. Fig. 5 shows the ability of the proposed model in characterising the entire stress strain response of granular soils under cyclic loading. The rate of cyclic densification can be well captured by varying the fractional derivative order, $\alpha$. The shear strain is observed to densify more quickly with a smaller value of $\alpha$.

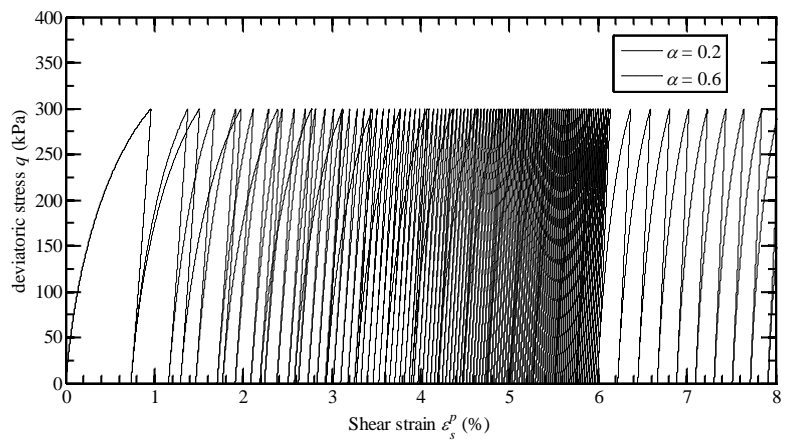

Fig. 5 Schematic representation of the effect of fractional order in modelling cyclic response

The above theoretical formula is an extension of the fractional order constitutive theory proposed by Yin et al. [26]. It incorporates the fractional calculus theory in traditional plasticity theory. Empirical models with $\alpha=1 / 3$ by Indraratna et al. [22] and Liu and Carter [41] are just special cases based on our proposed theory. The distinct difference between the proposed fractional order constitutive model and the traditional constitutive ones is its simplicity and yet vigorous in modelling the long-term deformation of granular soils.

\subsection{Explicit formula for predicting long-term deformation}

Under the triaxial testing condition, the increments principal mean stress, $p$, and deviator stress, $q$, can be linked to each other as $\dot{q}=3 \dot{p}$. Accordingly, combining Eqs. (33), (35), (41), and (43), the explicit expressions for the flow intensity can be given as

$$
d \bar{\varepsilon}^{p}=-\frac{\left(\frac{\partial g}{\partial p}+3 \frac{\partial g}{\partial q}\right) \dot{p}}{\frac{\partial g}{\partial p_{0}} \frac{\partial g}{\partial p} p_{0}}\left\|\frac{\partial g}{\partial \sigma}\right\| \frac{\Gamma(\alpha)}{\left(1+e_{0}\right) \xi}
$$

where $\xi=1 /\left(\lambda^{\prime}-\kappa\right)$ and

$$
\begin{gathered}
\frac{\partial g}{\partial q}=(a+1)\left(\frac{1}{M p}\right)\left(\frac{\eta}{M}\right)^{a} \\
\frac{\partial g}{\partial p}=(a+1) \frac{1}{p}\left[1-\left(\frac{\eta}{M}\right)^{a+1}\right] \\
\frac{\partial g}{\partial p_{0}}=-(a+1) \frac{1}{p_{0}} \\
\left\|\frac{\partial g}{\partial \boldsymbol{\sigma}}\right\|=\sqrt{\left(\frac{\partial g}{\partial p}\right)^{2}+\left(\frac{\partial g}{\partial q}\right)^{2}}
\end{gathered}
$$

In traditional plasticity model, the long-term deformation is implicitly calculated by accumulating the plastic strain of each loading cycle. However, due to the numerical errors built up during each step of iteration, the predictions are usually far from the experimental observations. To avoid complexity in predicting the long-term deformation of granular soils under drained triaxial loading condition, the plastic strain is supposed to be only induced by loading and unloading is totally elastic. The increment (e.g., $\Delta p$ ) of a cyclic load from its minimum value, $p_{\min }$, to its maximum value, $p_{\max }$, is regarded as one complete loading step. Moreover, according to the research by Wichtmann et al. [2, $3]$, the cyclic plastic flow of the long-term strain of granular soils can be approximately characterised by the modified Cambridge model consisting of the average principal loading stresses. Therefore, a general flow potential formed by the averaged mean principal stress $p^{\mathrm{av}}=\left(p_{\min }+p_{\max }\right) / 2$ and the averaged deviatroic stress $q^{\mathrm{av}}=\left(q_{\min }+q_{\max }\right) / 2$, is used to capture the cyclic flow in relation to the cumulative strain of each loading cycle. The superscript av means arithmetic average. The flow intensity can be rewritten as

$$
d \bar{\varepsilon}^{p}=\frac{\left[1+\frac{3-\eta^{\mathrm{av}}}{M}\left(\frac{\eta^{\mathrm{av}}}{M}\right)^{a}\right] \Delta p}{\left[1-\left(\frac{\eta^{\mathrm{av}}}{M}\right)^{a+1}\right](a+1)}\left\|\frac{\partial g}{\partial \sigma^{\mathrm{av}}}\right\| \frac{\Gamma(\alpha)}{\left(1+e_{0}\right) \xi}
$$

where $\eta^{\mathrm{av}}=q^{\mathrm{av}} / p^{\mathrm{av}}$. $\xi$ is found to depend on the loading condition, which can be expressed as $\xi=b_{1}\left(\Delta q / q^{\mathrm{av}}\right)^{b_{2}}+b_{3}\left(\Delta p / p^{\mathrm{av}}\right)^{b_{4}}$. Substituting Eq. (46) 
into Eq. (33) yields the explicit formula for granular soils under long-term cyclic loading.

$$
\begin{aligned}
\dot{\varepsilon}_{v}^{p} & =d \bar{\varepsilon}^{p} m_{p} \frac{N^{\alpha-1}}{\Gamma(\alpha)} \\
& =\left[1+\frac{3-\eta^{\mathrm{av}}}{M}\left(\frac{\eta^{\mathrm{av}}}{M}\right)^{a}\right] \frac{\Delta p}{p^{\mathrm{av}}} \frac{N^{\alpha-1}}{\left(1+e_{0}\right) \xi} \\
\dot{\varepsilon}_{s}^{p} & =d \bar{\varepsilon}^{p} m_{q} \frac{N^{\alpha-1}}{\Gamma(\alpha)} \\
& =\frac{\left[1+\frac{3-\eta^{\mathrm{av}}}{M}\left(\frac{\eta^{\mathrm{av}}}{M}\right)^{a}\right]}{\left(\frac{M}{\eta^{\mathrm{av}}}\right)^{a+1}-1} \frac{\Delta q}{q^{\mathrm{av}}} \frac{N^{\alpha-1}}{\left(1+e_{0}\right) \xi}
\end{aligned}
$$

\section{Model validation}

5.1 Model parameters
There are nine parameters, i.e., $G_{0}, v, \phi, a, \alpha, b_{1}, b_{2}, b_{3}$, and $b_{4}$, in the current model. Two elastic parameters, $G_{0}$ and $v$, can be determined by performing resonant column test or measuring the initial stress-strain gradient of the sample subjected to static triaxial loading ( $\varepsilon \leq 0.001 \%$ ).The critical state friction angle $\phi$ can be obtained by static triaxial test or from the reposed angle of the cone of the corresponding material deposited by slow centric lifting of a funnel. Parameter $a$ defines the flow direction and can be determined by using $\dot{\varepsilon}_{v} / \dot{\varepsilon}_{s}=0$ or by representing the relationship between $\dot{\varepsilon}_{v} / \dot{\varepsilon}_{s}$ and $\eta^{\text {av }}$. The fractional derivative order $\alpha$ determines the rate of strain accumulation and can be determined by fitting the relationship between $\ln \varepsilon$ and $\ln N$. Parameters, $b_{1}, b_{2}, b_{3}$, and $b_{4}$, can be obtained by regressing the plastic strain of the first loading cycle. Values of the model parameters along with the test conditions are listed in Table 1. As only the

\begin{tabular}{|c|c|c|c|c|c|c|c|c|c|c|c|}
\hline \multirow{2}{*}{ Test material } & \multicolumn{2}{|c|}{$p(\mathrm{kPa})$} & \multicolumn{2}{|c|}{$q(\mathrm{kPa})$} & \multirow{2}{*}{$\phi\left({ }^{\circ}\right)$} & \multirow{2}{*}{$\alpha$} & \multirow{2}{*}{$a$} & \multirow{2}{*}{$b_{1}$} & \multirow{2}{*}{$b_{2}$} & \multirow{2}{*}{$b_{3}$} & \multirow{2}{*}{$b_{4}$} \\
\hline & $\min$ & $\max$ & $\min$ & $\max$ & & & & & & & \\
\hline \multirow{4}{*}{ B1 [22] } & \multirow{4}{*}{75} & 184.7 & \multirow{4}{*}{45} & 374 & \multirow{4}{*}{46.4} & \multirow{4}{*}{0.12} & \multirow{4}{*}{0} & \multirow{4}{*}{0.0246} & \multirow{4}{*}{25.46} & \multirow{4}{*}{39.6} & \multirow{4}{*}{-26.47} \\
\hline & & 202.7 & & 428 & & & & & & & \\
\hline & & 220.7 & & 482 & & & & & & & \\
\hline & & 238.7 & & 536 & & & & & & & \\
\hline \multirow{3}{*}{ B2 [43] } & 45 & 106.7 & \multirow{3}{*}{45} & \multirow{3}{*}{230} & \multirow{3}{*}{46.4} & & & & & & \\
\hline & 75 & 136.7 & & & & 0.06 & 0 & 22.42 & 61.38 & 20833 & 7.151 \\
\hline & 135 & 196.7 & & & & & & & & & \\
\hline & 75 & 226.7 & & & & & & & & & \\
\hline B3 [43] & 135 & 286.7 & 45 & 500 & 46.2 & 0.06 & 0 & 27.83 & 69.86 & 3955 & 9.573 \\
\hline & 255 & 406.7 & & & & & & & & & \\
\hline B4 [43] & 135 & 370 & 45 & 750 & 467 & 006 & 0 & 0 & 0 & 32316 & 5043 \\
\hline$[4[4 J]$ & 255 & 490 & 4 & (50 & 40.1 & 0.00 & 0 & 0 & 0 & 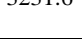 & 5.045 \\
\hline S1,2 [44] & 70 & 96.7 & 0 & 80 & 32.3 & 0.10 & 0 & 22.08 & 6.57 & 3.262 & -7.161 \\
\hline SG3,4 [44] & 100 & 201.7 & 0 & 200 & 38.0 & 0.13 & 0 & 18.91 & 10.78 & 2349 & -4.767 \\
\hline & & 451.7 & 0 & 500 & 50.0 & & 0 & & & & \\
\hline SW6,7,8 [44] & 0 & 120 & 0 & 300 & 43.8 & 0.12 & 0 & -18.23 & 11.32 & 58216 & -8.617 \\
\hline & 190 & 210 & 120 & 180 & & & & & & & \\
\hline SS1 [3] & 193.3 & 206.7 & 130 & 170 & 32.0 & 0.22 & 0.25 & 0.00752 & -5.387 & 541.4 & -0.285 \\
\hline & 196.7 & 203.3 & 140 & 160 & & & & & & & \\
\hline & 173.3 & 226.7 & 110 & 190 & & & & & & & \\
\hline SS3 [3] & 180 & 220 & 120 & 180 & 32.9 & 0.21 & 0.25 & 371.6 & -0.692 & 0.081 & 14.46 \\
\hline & 187.6 & 213.3 & 130 & 170 & & & & & & & \\
\hline & 193.3 & 206.7 & 140 & 160 & & & & & & & \\
\hline & 173.3 & 226.7 & 110 & 190 & & & & & & & \\
\hline SS4 [3] & 180 & 220 & 120 & 180 & 331 & 027 & 0.25 & 1108 & $-3,503$ & 780 & -0.027 \\
\hline $304[0]$ & 187.6 & 213.3 & 130 & 170 & 33.1 & 0.21 & 0.25 & 1.100 & -3.005 & 700 & -0.021 \\
\hline & 193.3 & 206.7 & 140 & 160 & & & & & & & \\
\hline & 187.6 & 213.3 & 130 & 170 & & & & & & & \\
\hline SS2 [3] & 190 & 210 & 135 & 165 & 342 & 037 & 025 & 0006 & -3472 & 4802 & - \\
\hline (302 [J] & 193.3 & 206.7 & 140 & 160 & 34.2 & $0.5 \prime$ & 0.25 & 0.000 & $-3.4 / 2$ & 4.002 & -0.250 \\
\hline & 195.7 & 204.3 & 143.5 & 156.5 & & & & & & & \\
\hline & & & 30 & 70 & & & & & & & \\
\hline & & & 80 & 120 & & & & & & & \\
\hline SS5 [3] & 1867 & 2133 & 130 & 170 & 327 & 021 & 0.25 & 1749 & -1.014 & 1341 & -0.563 \\
\hline (5] & 100. & 210.5 & 155 & 195 & 02.1 & 0.21 & 0.25 & 174.0 & -1.014 & 104.1 & -0.005 \\
\hline & & & 180 & 220 & & & & & & & \\
\hline & & & 205 & 245 & & & & & & & \\
\hline
\end{tabular}
permanent deformation is evaluated in this study, elastic parameters are omitted here for clarity.

Table 1 Model parameters and test conditions for different granular soils 


\subsection{Model performance}

The model is validated with laboratory experimental results reported by Wichtmann et al. [3], Indraratna et al. [22], Lackenby [43], as well as Lekarp and Dawson [44]. Test conditions can be found in Table 1 .

Figs. 6 to 10 shows the long-term deformation of different sands [3] tested under different cyclic loading conditions. All the sands used were natural sub-angular quartz aggregates taken from a sand pit near Dorsten, Germany. Detailed physical properties can be found elsewhere in [3] and are omitted here for simplicity. Figs. 6 to 9 present the prediction results of the permanent deformation of different sands (SS1, SS2 SS3, SS4) under different deviator stress amplitudes. With the increase of the number of loading cycles the residual strain increases rapidly and then approach stable. Higher stress amplitude is observed to cause higher sand deformation. Good agreements between the model predictions and the corresponding experimental results are observed. Fig. 10 shows the permanent deformation of sand No. SS5 with different deviator stresses. With the increase of the deviator stress, a higher permanent deformation is observed, which can be well captured by the proposed model.

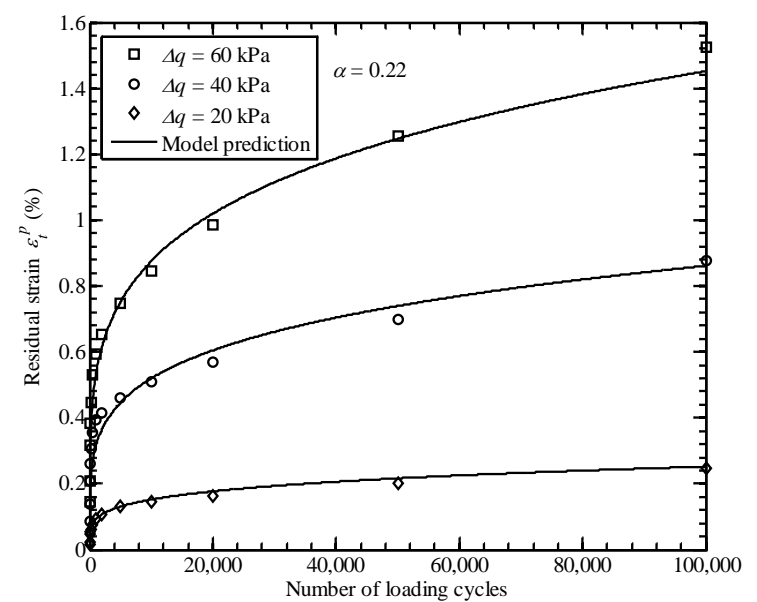

Fig. 6 Permanent deformation of sand (SS1) tested under different stress amplitudes

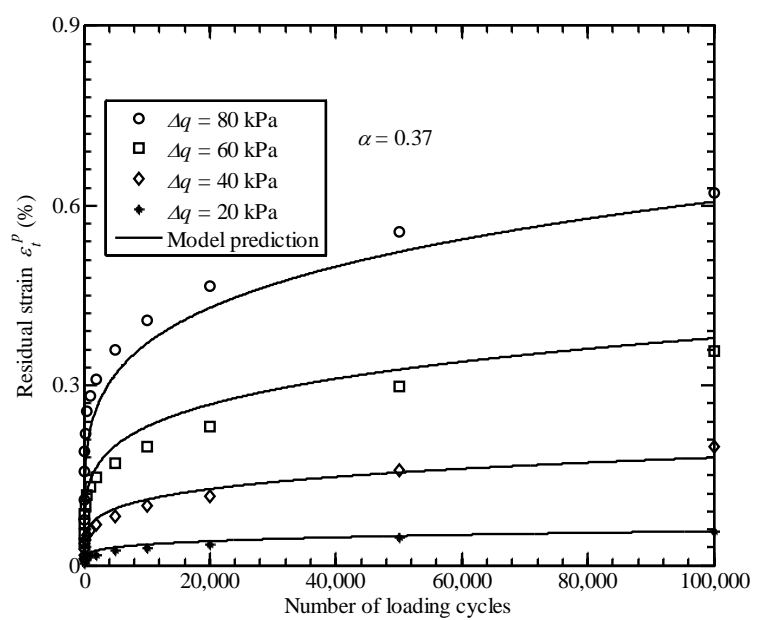

Fig. 7 Permanent deformation of sand (SS2) tested under differen stress amplitudes

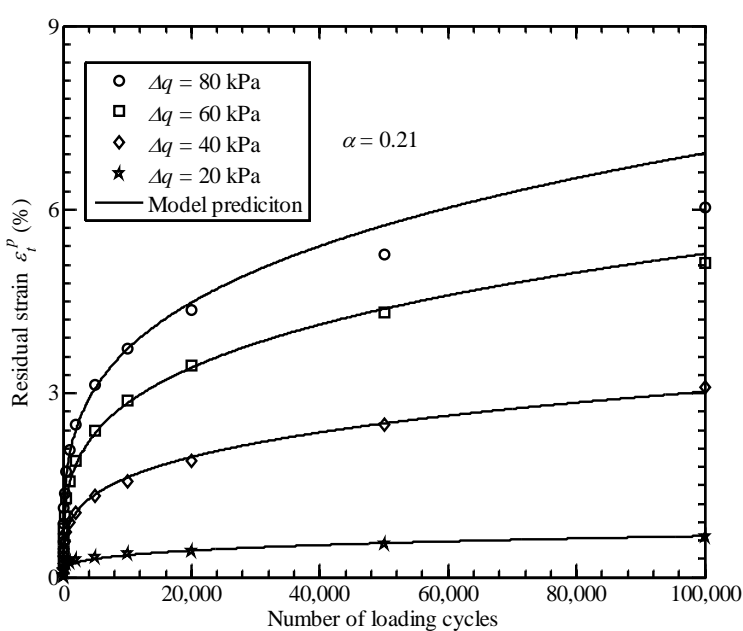

Fig. 8 Permanent deformation of sand (SS3) tested under different stress amplitudes

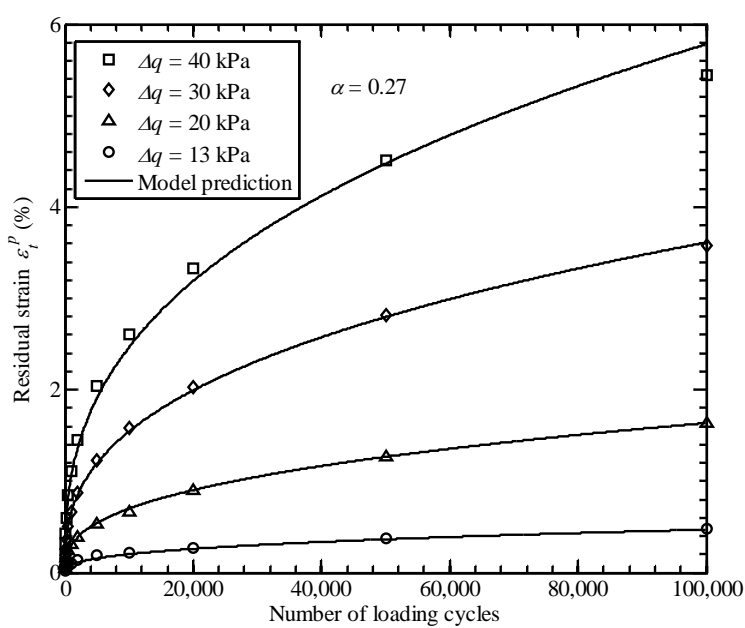

Fig. 9 Permanent deformation of sand (SS4) tested under different stress amplitudes

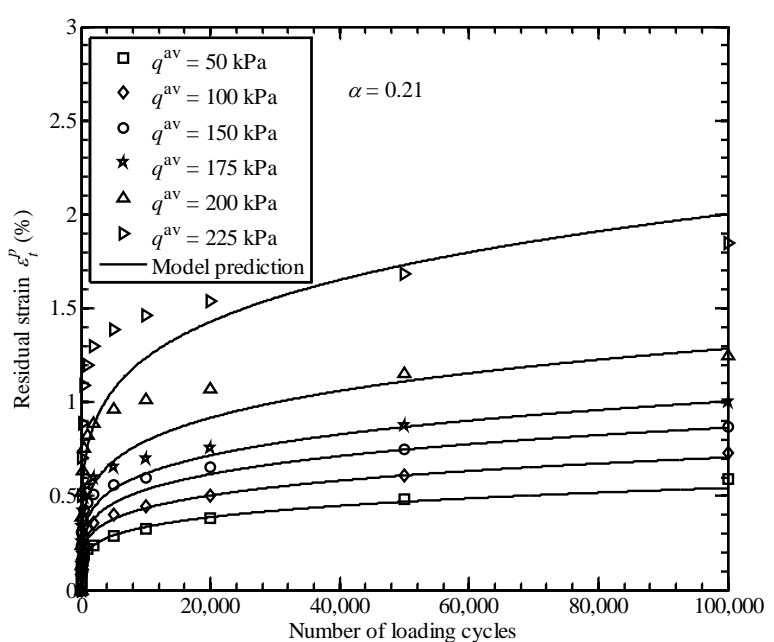

Fig. 10 Permanent deformation of sand (SS5) tested under different deviatoric stresses

Figs. 11 to 14 present the long-term deformation of different crushed rocks tested under different mean principal and deviator stresses. The crushed rock is a dark-coloured volcanic (igneous) rock containing plagioclase, feldspar, and augite. The physical and durability properties of the 
crushed rocks can be found in [43]. Four test results under different loading frequency are presented in Fig. 11. The corresponding stress amplitudes were calculated in accordance with Esveld [45] for 30 ton axle loading. As illustrated, with the increase of the loading stress, the permanent deformation increases, which can be well characterised by the proposed model. Figs. 12 to14 presents the comparison between the model prediction and the experimental results obtained under different average mean principal stresses. The proposed model is also capable of characterising the long-term deformation of the crushed rocks under various mean principal stresses.

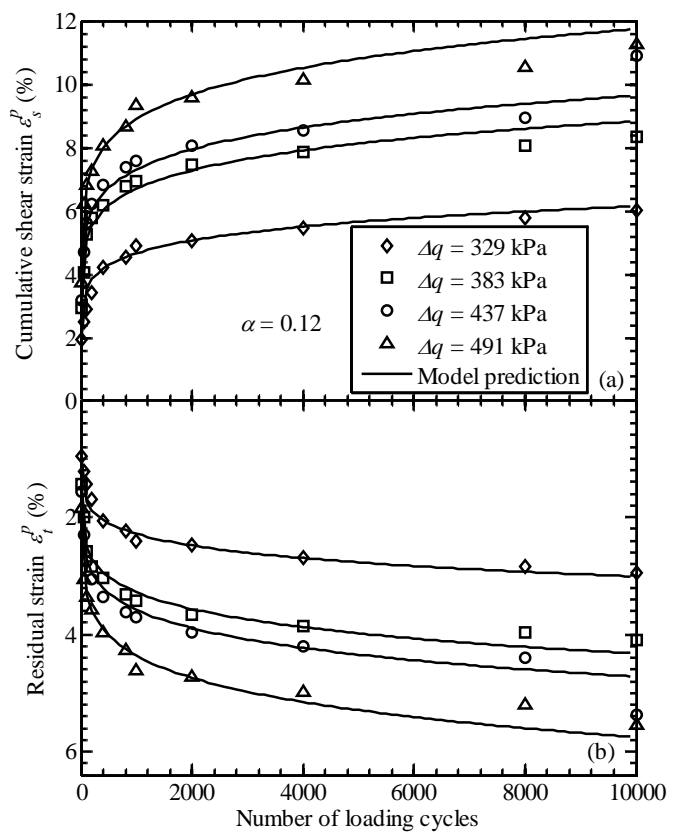

Fig. 11 Permanent deformation of ballast (B1) tested under mean principal and deviator stresses

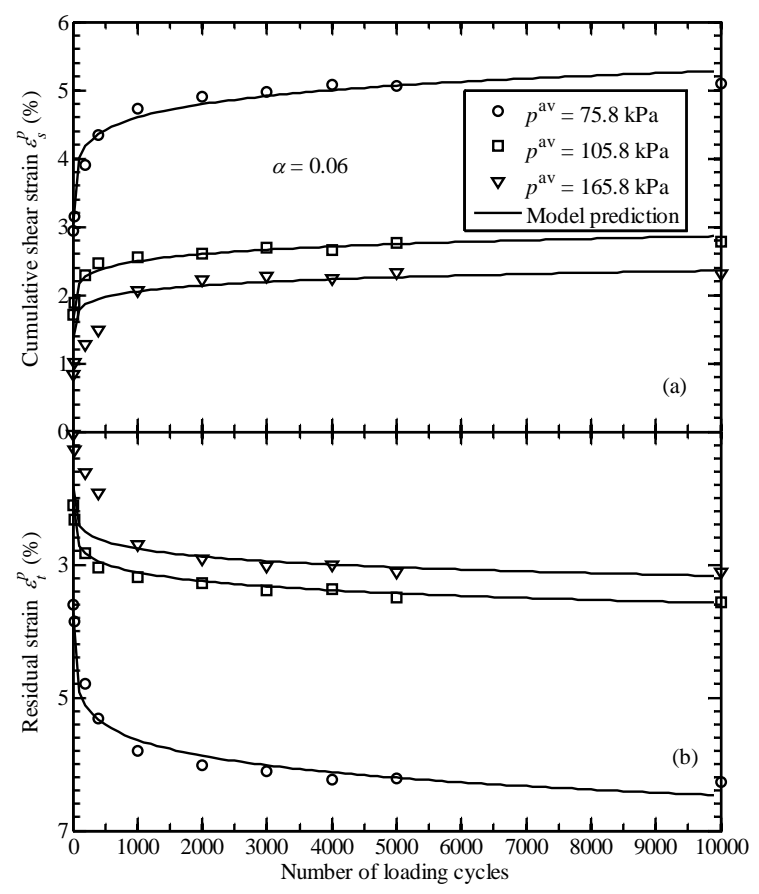

Fig. 12 Permanent deformation of ballast (B2) tested under various mean principal stresses

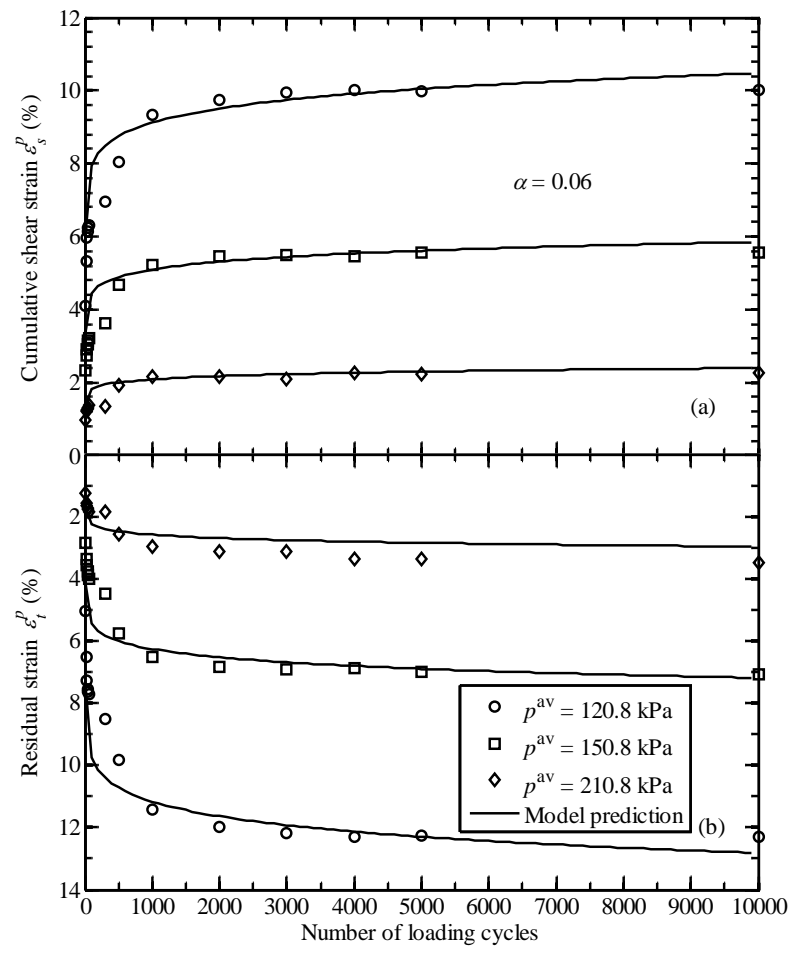

Fig. 13 Permanent deformation of ballast (B3) tested under various mean principal stresses

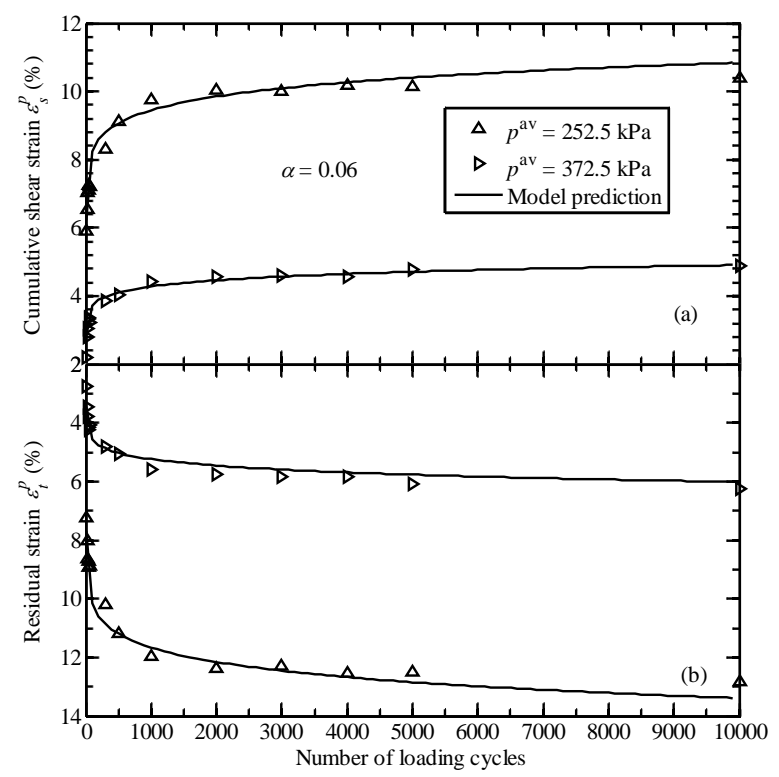

Fig. 14 Permanent deformation of ballast (B4) tested under different mean principal stresses

Permanent axial strains of three different pavement materials are also simulated in Fig. 15. The material types include Leighton Buzzard sands ( $S$ ), the sand and gravel (SG), and the slate waste (SW). The SG and SW were tested in a triaxial apparatus, while the $\mathrm{S}$ was tested in a hollow cylinder apparatus. As can be seen, the permanent deformation of different pavement materials tested under different loading conditions can also be well represented using the current model. 


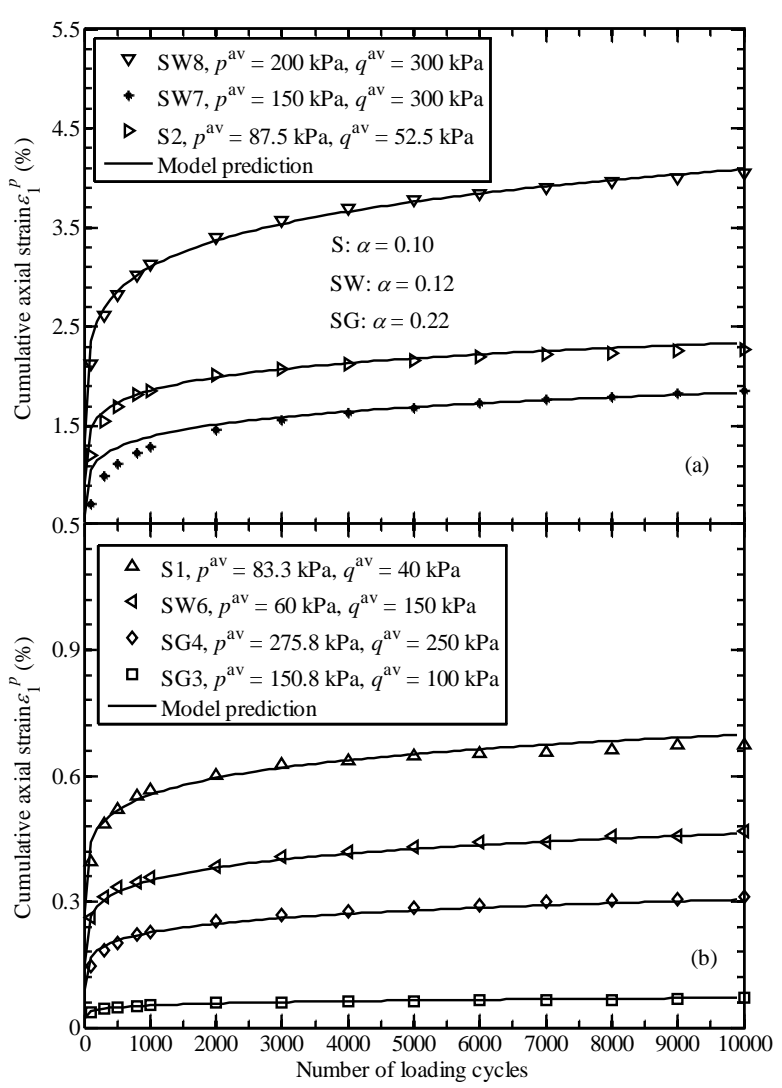

Fig. 15 Permanent deformation of pavement materials tested under different loading stresses

\section{Conclusions}

Fractional derivatives were found to be a powerful instrument in characterising the memory-intensive phenomena, such as the soil deformation and chemical diffusion, etc. Previous work [26] has demonstrated the flexible ability of fractional derivatives in modelling the static deformation of geomaterials. However, the physical origin of the fractional derivative order has not yet been explored. In this study, an attempt has been made to investigate the connection between the fractional derivative order and the fractal dimension of granular soils. Then a modified elasto-plastic constitutive model was proposed for granular soils by incorporating the theory of fractional calculus, and was further supplemented by experimental data. In the current model, a cyclic flow rule considering the effect of particle breakage was also proposed. The concept introduced for modelling long-term deformation was simplified, and it was an extension of a monotonic loading model proposed earlier by Yin et al. [26]. Deformation under the first loading cycle was considered as virgin loading, and the deformation under subsequent loading cycles was considered a function of the first loading cycle. The effect of the stress history has been taken into account by using the fractional derivative order. The proposed model degrades to the traditional plasticity model with the fractional derivative order equal to unit. With the decrease of the fractional derivative order, the model was observed to exhibit an increasing rate for reaching cyclic densification.
Predicted results have been compared with the experimental data to validate the model accuracy. It was observed that the proposed model can well characterise the long-term deformation of various granular soils under different cyclic loading conditions.

Acknowledgements The authors would like to thank Professor W. Chen and Dr Xiaodi Zhang in the Department of Engineering Mechanics, Hohai University, for their kind instruction and continuous inspiration on several fundamentals of the fractional calculus during the undergraduate period. The authors would also like to thank Mr. Rodger Paton at University of Wollongong for his technical assistance in computer programing. The financial supports provided by the Fundamental Research Funds (Grant No. 106112015CDJXY200008) is appreciated.

\section{References}

1. Aursudkij, B., McDowell, G.R., Collop, A.C.: Cyclic loading of railway ballast under triaxial conditions and in a railway test facility. Granular Matter 11(6), 391-401 (2009)

2. Wichtmann, T., Niemunis, A., Triantafyllidis, T.: On the determination of a set of material constants for a highcycle accumulation model for non-cohesive soils. Int. J. Numer. Anal. Meth. Geomech. 34(4), 409-440 (2010)

3. Wichtmann, T., Niemunis, A., Triantafyllidis, T.H.: Validation and calibration of a high-cycle accumulation model based on cyclic triaxial tests on eight sands. Soils Found. 49(5), 711-728 (2009)

4. Rahman, M., Baki, M., Lo, S.: Prediction of undrained monotonic and cyclic liquefaction behavior of sand with fines based on the equivalent granular state parameter. Int. J. Geomech. 14(2), 254-266 (2014)

5. Indraratna, B., Thakur, P.K., Vinod, J.S.: Experimental and numerical study of railway ballast behavior under cyclic loading. Int. J. Geomech. 10(4), 136-144 (2010)

6. Chang, C., Whitman, R.: Drained Permanent Deformation of Sand Due to Cyclic Loading. J. Geotech. Eng. 114(10), 1164-1180 (1988)

7. Khalili, N., Habte, M., Valliappan, S.: A bounding surface plasticity model for cyclic loading of granular soils. Int. J. Numer. Meth. Eng. 63(14), 1939-1960 (2005)

8. Liu, H.B., Zou, D.G.: Associated Generalized Plasticity Framework for Modeling Gravelly Soils Considering Particle Breakage. J. Eng Mech. 139(5), 606-615 (2013)

9. Sevi, A., Ge, L.: Cyclic Behaviors of Railroad Ballast within the Parallel Gradation Scaling Framework. J. Mater. Civil Eng. 24(7), 797-804 (2012)

10. Suiker, A.S., Selig, E.T., Frenkel, R.: Static and cyclic triaxial testing of ballast and subballast. J. Geotech. Geoenviron. Eng. 131(6), 771-782 (2005)

11. Sun, Y., Xiao, Y., Hanif, K.: Compressibility dependence on grain size distribution and relative density in sands. Sci. China Tech. Sci. 58(3), 443-448 (2015) 
12. Sun, Y., Xiao, Y., Ju, W.: Bounding surface model for ballast with additional attention on the evolution of particle size distribution. Sci. China Tech. Sci. 57(7), 1352-1360 (2014)

13. Sun, Y., Indraratna, B., Nimbalkar, S.: Threedimensional characterisation of particle size and shape for ballast. Géotechnique Letters 4, 197-202 (2014)

14. Kan, M., Taiebat, H., Khalili, N.: Simplified mapping rule for bounding surface simulation of complex loading paths in granular materials. Int. J. Geomech. 14(2), 239253 (2014)

15. Xiao, Y., Liu, H.L., Chen Y. et al.: Influence of intermediate principal stress on the strength and dilatancy behavior of rockfill material. J. Geotech. Geoenviron. Eng. 140, 04014064 (2014) DOI 10.1061/(ASCE)GT.1943-5606.0001178

16. Liu, H., Zou, D., Liu, J.: Constitutive modeling of dense gravelly soils subjected to cyclic loading. Int. J. Numer. Anal. Meth Geomech. 38(14), 1503-1518 (2014)

17. Indraratna, B., Lackenby, J., Christie, D.: Effect of confining pressure on the degradation of ballast under cyclic loading. Géotechnique 55(4), 325-328 (2005)

18. Sun, Q.D., Indraratna, B., Nimbalkar, S.: Effect of cyclic loading frequency on the permanent deformation and degradation of railway ballast. Géotechnique 64, 746-751 (2014)

19. Darve, F., Labanieh, S.: Incremental constitutive law for sands and clays: Simulations of monotonic and cyclic tests. Int. J. Numer. Anal. Meth. Geomech. 6(2), 243275 (1982)

20. McDowell, G.R., de Bono, J.P., Yue, P., et al.: Micro mechanics of isotropic normal compression. Géotechnique Lett. 3, 166-172 (2013)

21. McDowell, G.R., Daniell, C.M.: Fractal compression of soil. Géotechnique 51, 173-176 (2001)

22. Indraratna, B., Thakur, P.K., Vinod, J.S., et al.: Semiempirical cyclic densification model for ballast incorporating particle breakage. Int. J. Geomech. 12(3), 260-271 (2012)

23. Woo, S.I. Salgado, R.: Bounding surface modeling of sand with consideration of fabric and its evolution during monotonic shearing. Int. J. Solids Struct. 63(0), 277-288 (2015)

24. Sun, Y., Liu, H.L., Xiao, Y., et al.: Modeling of rheological behavior of geomaterials based on fractional viscoelastic equation with variable parameters, Instrumentation, Testing, and Modeling of Soil and Rock Behavior, 107-114 (2011)

25. Yin, D., Zhang W., Cheng C., et al.: Fractional timedependent Bingham model for muddy clay. J. NonNewtonian Fluid Mech. 187: 32-35 (2012)

26. Yin, D., Zhang, W. Cheng C., et al.: Fractional order constitutive model of geomaterials under the condition of triaxial test. Int. J. Numer. Anal. Meth. Geomech. 37(8), 961-972 (2013)

27. Chen, W.: Time-space fabric underlying anomalous diffusion. Chaos Soliton Fract. 28(4): 923-929 (2006)
28. Chen, W., Sun, H., Zhang X.D., et al.: Anomalous diffusion modeling by fractal and fractional derivatives. Comput. Math. Appl. 59(5): 1754-1758 (2010)

29. Fu, Z.J., Chen, W., Yang, H.T.: Boundary particle method for Laplace transformed time fractional diffusion equations. J. Comput. Phys. 235: 52-66 (2013)

30. Kimoto, S., Shahbodagh, K.B., Mirjalili, M., et al.: Cyclic elastoviscoplastic constitutive model for clay considering nonlinear kinematic hardening rules and structural degradation. Int. J. Geomech. (2015) DOI doi:10.1061/(ASCE)GM.1943-5622.0000327

31. Kaliakin, V.N. Dafalias, Y.F.: Theoretical aspects of the elastoplastic-viscoplastic bounding surface model for cohesive soils. Soils Found. 30(3), 11-24 (1990)

32. Suiker, A.S.J., de Borst, R.: A numerical model for the cyclic deterioration of railway tracks. Int. J. Numer. Meth. Eng. 57(4), 441-470 (2003)

33. Niemunis, A., Wichtmann, T., Triantafyllidis, T.: A high-cycle accumulation model for sand. Comput. Geotech. 32(4), 245-263 (2005)

34. François, S., Karg, C., Haegeman, W., et al.: A numerical model for foundation settlements due to deformation accumulation in granular soils under repeated small amplitude dynamic loading. Int. J. Numer. Anal. Meth. Geomech. 34(3), 273-296 (2010)

35. Locke, M., Indraratna, B., Adikari, G.: Time-dependent particle transport through granular filters. J. Geotech. Geoenviron. Eng. 127(6), 521-529 (2001)

36. Indraratna, B., Raut, A.K., Khabbaz, H.: Constrictionbased retention criterion for granular filter design. J. Geotech. Geoenviron. Eng. 133(3), 266-276 (2007)

37. Dodds, P.S. Weitz, J.S.: Packing-limited growth. Phys. Rev. E 65(5), 056108 (2002)

38. Delaney, G.W., Hutzler, S. Aste, T.: Relation between grain shape and fractal properties in random Apollonian packing with grain rotation. Phys. Rev. Lett. 101(12), 120602 (2008)

39. Russell, A.R.: Water retention characteristics of soils with double porosity. Eur. J. Soil Sci. 61(3), 412-424 (2010)

40. McDowell, G.: A family of yield loci based on micro mechanics. Soils Found. 40(6), 133-137 (2000)

41. Liu, M. Carter, J.P.: On the volumetric deformation of reconstituted soils. Int. J. Numer. Anal. Meth. Geomech. 24(2), 101-133 (2000)

42. Chen, C., Ge, L., Zhang, J.: Modeling permanent deformation of unbound granular materials under repeated loads. Int. J. Geomech. 10(6), 236-241 (2010)

43. Lackenby, J.: Triaxial behaviour of ballast and the role of confining pressure under cyclic loading. $\mathrm{PhD}$ thesis, University of Wollongong. (2006)

44. Lekarp, F., Dawson, A.: Modelling permanent deformation behaviour of unbound granular materials. Constr. Build Mater . 12(1), 9-18 (1998)

45. Esveld, C.: Modern railway track. Zaltbommel, The Netherlands: MRT Productions. (2001) 